\title{
Intramedullary Arachnoid Cyst of the Cervical Spine: Case Report and Literature Review
}

\section{Cisto aracnoide intramedular da coluna cervical: relato de caso e revisão da literatura}

\author{
Saleh Baeesa ${ }^{1} \quad$ Abdalrahman Aljameely ${ }^{1}$ \\ ${ }^{1}$ Division of Neurosurgery, Faculty of Medicine, King Abdulaziz \\ University, Jeddah, Saudi Arabia \\ Arq Bras Neurocir 2017;36:256-259.

\begin{abstract}
Address for correspondence Saleh Baeesa, Division of Neurosurgery, Faculty of Medicine, King Abdulaziz University, Jeddah, Saudi Arabia (e-mail: sbaeesa@kau.edu.sa).
\end{abstract}

\begin{abstract}
Intramedullary arachnoid cysts of the spinal cord are extremely rare benign lesions of unclear pathogenesis. To our knowledge, only 21 cases were reported in the literature, 10 of which involved the cervical spine. We report the case of a 47-year-old female who presented with a symptomatic spinal intramedullary arachnoid cyst (SIAC). Magnetic resonance imaging scan of the cervical spine demonstrated an intramedullary arachnoid cyst at C3-C5 level. The patient had a cervical laminectomy and cysto-subarachnoid shunt with rapid and excellent clinical recovery and no

\section{Keywords}

- arachnoid cyst

- intramedullary

- cervical spine

- case report

\section{Resumo}

Palavras-chave

- cisto aracnoide

- intramedular

- coluna cervical

- relato de cas recurrence at 2-year follow-up. Intramedullary arachnoid cysts should be considered in the differential diagnosis of intramedullary cystic lesions of the spinal cord. Their pathogenesis and natural history are not well defined in the literature. However, a cysto-subarachnoid shunt can be performed with excellent long-term clinical and radiological results.

Os cistos aracnoides intramedulares são lesões benignas extremamente raras e de origem desconhecida. Que seja do conhecimento dos autores, apenas 21 casos foram publicados, mas com apenas 10 envolvendo a coluna cervical. Os autores reportam o caso clínico de uma paciente do sexo feminino, de 47 anos de idade, com um cisto aracnoide intramedular sintomático que a ressonância magnética da coluna cervical demonstrou localizar-se no nível C3-C5. A paciente foi submetida a laminectomia cervical e derivação cisto-subaracnoide com recuperação neurológica rápida e significativa, sem recorrência após 2 anos de acompanhamento.

Os cistos aracnoides intramedulares devem ser considerados no diagnóstico diferencial das lesões císticas da medula espinhal. A patogenia, bem como a história natural, não está bem estabelecida na literatura. A derivação cisto-subaracnoide é exequível com excelentes resultados clínicos e imagiológicos.
\end{abstract}

\section{Introduction}

Spinal arachnoid cysts (SACs) are uncommon benign lesions frequently encountered in the extra or intradural spaces, rarely found as an intramedullary lesion. ${ }^{1}$ To our knowledge, only 21

received

August 15, 2017

accepted

August 24, 2017

published online

September 14, 2017

10.1055/s-0037-1606816. ISSN $0103-5355$. spinal intramedullary arachnoid cyst (SIAC) cases were reported in the literature, 10 (48\%) of which involved the cervical spine. Their origin remains unclear, and many causes have been postulated. ${ }^{1}$

Copyright @ 2017 by Thieme Revinter

Publicações Ltda, Rio de Janeiro, Brazil

License terms

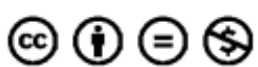




\section{Case}

A 47-year-old female presented with right-hand pain and numbness associated with neck pain ongoing for 1 year. Her symptoms progressed over 5 weeks with proximally spreading numbness to involve both arms and trunk, weak handgrip of the right hand, and tendency to fall towards the right side. She had intermittent difficulty controlling her sphincters over the last week of presentation to the clinic. Her past medical history was unremarkable and physical examination was within normal parameters: there was no neck tenderness or limitation of movement. Neurological examination revealed normal cognitive and cranial nerves examination. She was ambulating with the assistance of a cane and had marked right arm weakness with power grade of $3 / 5$ at elbow flexion and extension, fingers flexion and abduction; however, there was no atrophy. The power in the left upper limb and lower limbs was within normal range. The sensory examination was disturbed only in the right arm with decreased touch and pain sensation, but proprioception and vibration senses were intact. Deep tendon reflexes were decreased in the right upper limb but were exaggerated in the left upper and lower limbs.

Magnetic resonance imaging (MRI) study of the cervical spine showed a well-demarcated intramedullary cystic lesion at the C3-C5 vertebral level that measured $36 \mathrm{~mm} \times 13 \mathrm{~mm}$ at maximum diameter ( $\boldsymbol{- F i g . 1}$ ). The lesion was centralized with more eccentric extension toward the right side. The cyst was hypointense on T1-weighted and hyperintense on T2-weighted images and showed neither restriction on diffusion weighted images nor enhancement after intravenous gadolinium administration. No other lesions were visualized on the MRI of the brain or of the remaining parts of the spine.

Surgery was performed through 2-level laminectomy and durotomy and microsurgical decompression of the cyst through vertical $3 \mathrm{~mm}$ myelotomy at the right dorsal root entry zone (DREZ) of C4 rootlets. Once the cyst was encountered, clear cerebrospinal fluid (CSF) came out with medium pressure. A T-tube shunt (Medtronic, Minneapolis, MN, USA) was inserted through the myelotomy into the cyst cavity, and the $50 \mathrm{~mm}$-long distal tip was placed in the subarachnoid space and directed cephalad toward the cisterna magna (-Fig. 2). The pia was closed with polypropylene $5 / 0$ suture anchoring the tube in place to prevent dislodgement, and then watertight dural and musculocutaneous flap closures were performed.

The patient's postoperative course was uneventful; she had immediate marked relief of the radiculopathy with no new neurological deficit. When patient was discharged on the $5^{\text {th }}$ postoperative day, she was ambulating unassisted, with marked improvement of muscle power and sensation $(+4 / 5)$ of the right arm.

The patient continued to improve regarding the radiculopathy and motor power and sensation until fully recovered by the 6-month follow-up period. Serial MRI scan of the cervical spine revealed a progressive decrease of the cyst size, which remained stable at the 2-year follow-up; the shunt tube remained at the same position (-Fig. 3 ).
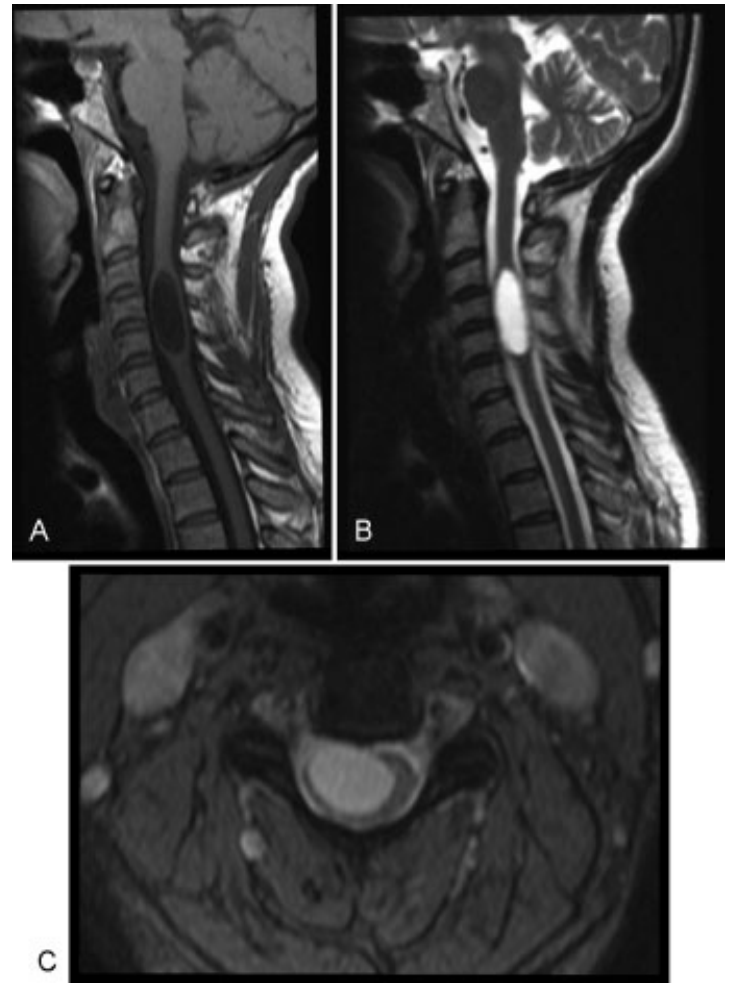

Fig. 1 Magnetic resonance imaging of the cervical spine is demonstrating a $36 \times 13 \mathrm{~mm}$ intramedullary arachnoid cyst. (A) The lesion is hypointense in the sagittal T1-WI scan. (B) The lesion has a similar intensity of cerebrospinal fluid, but it is hyperintense on the sagittal T2-WI scan. (C) the lesion has a significant mass effect, especially at the C4-C5 level.
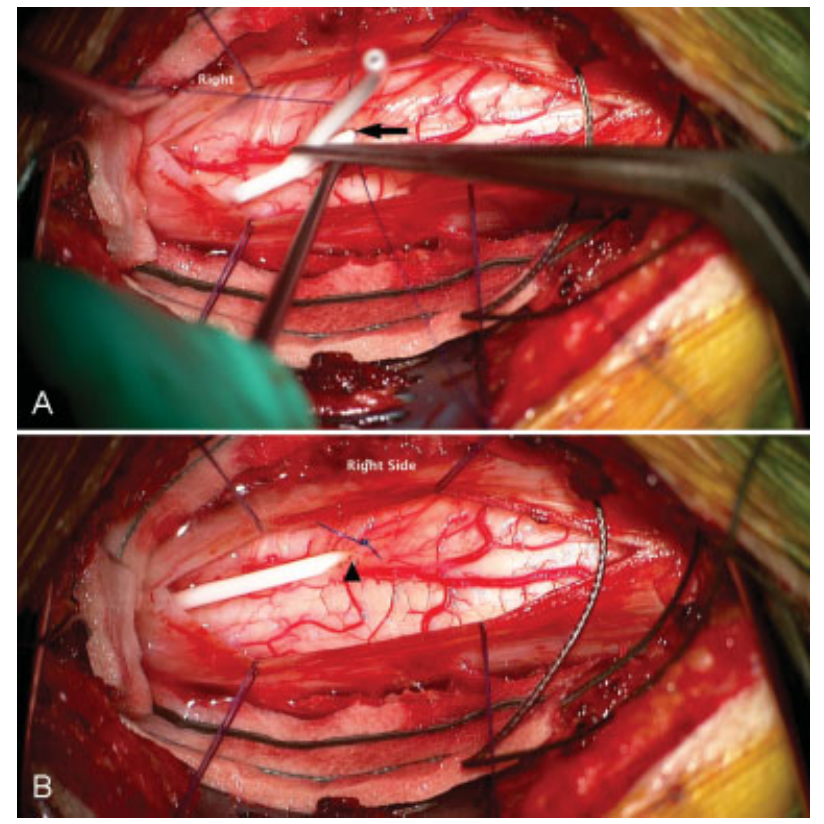

Fig. 2 Intraoperative microscopic photographs after laminectomy are demonstrating insertion of the cysto-subarachnoid shunt. (A) Exposure at C3-C5 spinal cord showing DREZ myelotomy (arrow) and inserting the caudal limb of the T-tube shunt first, followed by the cephalic one. (B) The shunt was inserted, secured with the closure of the myelotomy (arrowhead), and the draining end was placed cephalad in the subarachnoid space. 

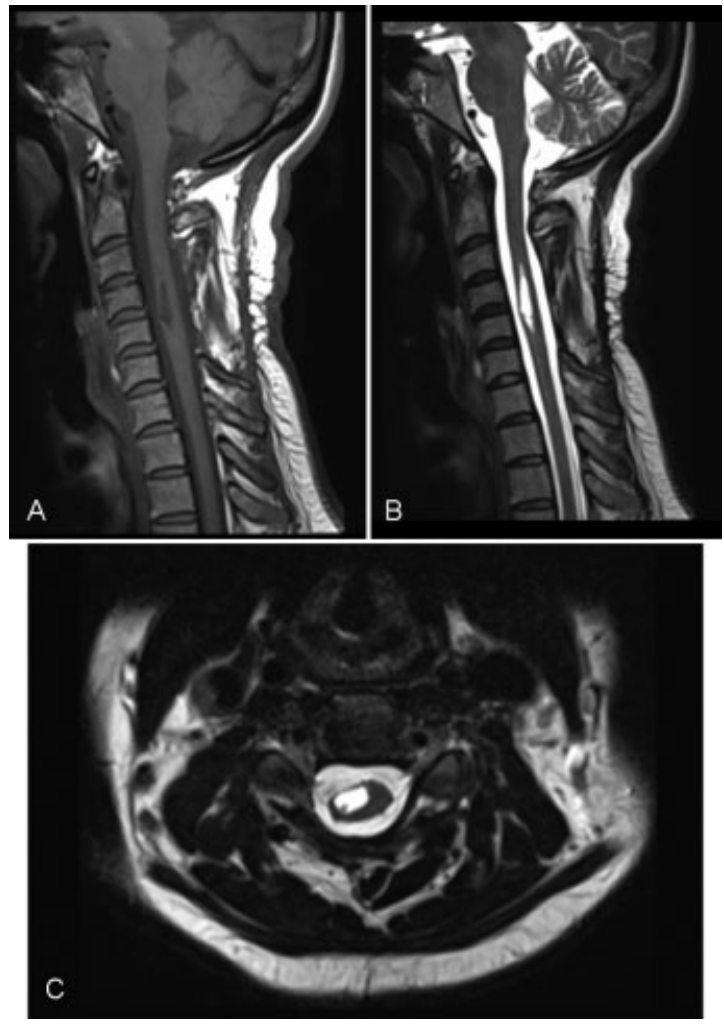

Fig. 3 Magnetic resonance imaging of the cervical spine at 2-year follow-up demonstrating significant resolution of intramedullary arachnoid cyst after a cysto-subarachnoid shunt. (A) There is marked reduction of the cyst size on the sagittal T1-WI scan and (B) sagittal T2WI scan and (C) axial T2-WI scan with an adequate position of the shunt.

\section{Discussion}

Spinal intramedullary arachnoid cysts are a rare neurosurgical condition, and different considerations about their possible etiology were proposed. Although not yet well understood, most reports considered SACs as congenital of origin due to their higher incidence in pediatric age, association with other congenital central nervous system abnormalities and their tendency to occur in families. ${ }^{2}$ Fortuna et al postulated that congenital abnormalities in the distribution of arachnoid trabeculations lead to misplaced cellular elements in the intramedullary region resulting in an embryonic malformation and cyst development. ${ }^{3}$ Acquired SACs are believed to be a result of the arachnoiditis following lumbar puncture, infection, epidural anesthesia, or procedures of spinal surgery. ${ }^{4}$

The majority of the 21 reported cases of SIACs were located in the thoracic region (14 cases), and only 6 cases were in the cervical spine. Due to their rarity, their natural history is not well determined. ${ }^{2}$ However, by reviewing the previous cases of SIACs that were reported in different areas of the spine, they are most likely of a slowly progressive nature, which is related to different mechanisms that lead to cyst expansion, enough to cause cord or nerve root compression.

Since the first description of SIACs of the cervical spine by Sharma et al, ${ }^{5}$ five cases have been reported in the literature (-Table 1). ${ }^{6-10}$ The most common presenting symptom

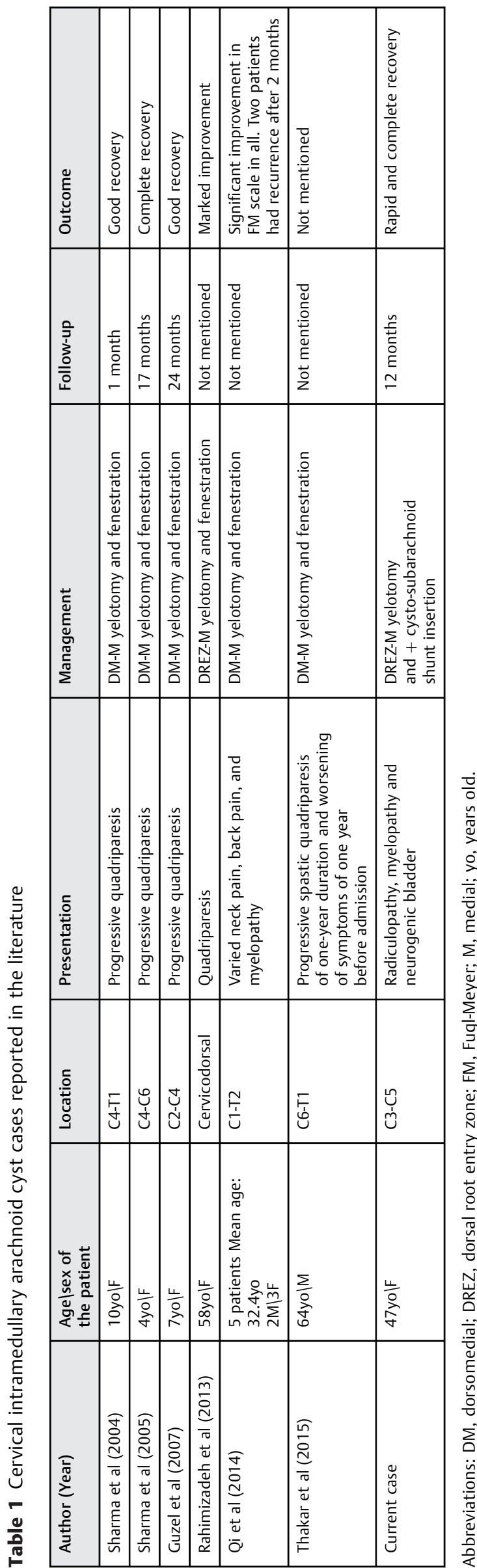


was progressive quadriparesis. No history of trauma or neurological anomalies were associated. Infection was thought to be a precipitating factor in one case. ${ }^{6}$ Although SIACs might have a mass effect on the central canal, no known reported cases developed an obstructive hydrocephalus or syringomyelia. Hemorrhagic changes of SIACs were described only once by Thakar $\mathrm{S}$ et al. ${ }^{7}$ Rahimizadeh et al described the first case of SIAC of the cervical spine coexisting with severe cervical spondylosis; they suggested targeting both pathologies in a single-stage operation for proper management. ${ }^{8}$

Magnetic resonance imaging remains the investigation of choice for all SACs ${ }^{6}$ The absence of pointed craniocaudal poles of the lesion and solid component associated with the cyst may rule out other pathologies as syringomyelia, pilocytic astrocytoma, oligodendrogliomas, ependymomas or epidermoid cysts.

Surgical treatment is the rule for symptomatic SIACs. The use of intraoperative fluoroscopy or ultrasound may be necessary to identify the exact spine segment location of the cyst. The collapse of the cyst is usually achieved with midline or DREZ myelotomy. The length of the incision varied according to the size of the cyst, and sometimes a dense adhesion between the cyst wall and the spinal cord is found, especially in chronic cases. Separation of the cyst wall from the spinal cord should not be performed as it is very adherent and it is associated with unnecessary high morbidity; such a difficulty was reported by Qi et al. ${ }^{9}$

Good to excellent results were encountered immediately in most of the SIACs that were managed by fenestration, but because no documented long-term follow-up has been recorded, the risk of cyst recurrence, adhesions and fibrosis is an important issue that needs further attention.

\section{Conclusion}

Intramedullary arachnoid cysts should be considered in the differential diagnosis of intramedullary cystic lesions. We recommend the insertion of a cysto-subarachnoid shunt; this procedure will assure a long-term free communication and lower the recurrence rate, which was successfully achieved in our case. However, the rarity of this instance makes it very difficult to conduct case series, retrospective and prospective studies.

\section{References}

1 Alugolu R, Arradi V, Sahu BP. Intramedullary arachnoid cyst in an adult: Case report and review. Asian J Neurosurg 2016;11(01): 70

2 Novegno F, Umana G, Di Muro L, Fraioli B, Fraioli MF. Spinal intramedullary arachnoid cyst: case report and literature review. Spine J 2014; 14(06):e9-e15

3 Fortuna A, Mercuri S. Intradural spinal cysts. Acta Neurochir (Wien) 1983;68(3-4):289-314

4 Nogués MA, Merello M, Leiguarda R, Guevara J, Figari A. Subarachnoid and intramedullary cysts secondary to epidural anesthesia for gynecological surgery. Eur Neurol 1992;32(02):99-101

5 Sharma A, Sayal P, Badhe P, Pandey A, Diyora B, Ingale H. Spinal intramedullary arachnoid cyst. Indian J Pediatr 2004;71(12): e65-e67

6 Guzel A, Tatli M, Yilmaz F, Bavbek M. Unusual presentation of cervical spinal intramedullary arachnoid cyst in childhood: case report and review of the literature. Pediatr Neurosurg 2007; 43(01):50-53

7 Thakar S, Hegde AS. A hemorrhagic cervical intramedullary arachnoid cyst. Spine J 2016;16(03):e173-e174

8 Rahimizadeh A, Soufiani H. Intramedullary arachnoid cyst in association with cervical spondylosis: case report. Spine J 2013; 13(10):e21-e25

9 Qi J, Yang J, Wang G. A novel five-category multimodal T1-weighted and T2-weighted magnetic resonance imagingbased stratification system for the selection of spinal arachnoid cyst treatment: a 15-year experience of 81 cases. Neuropsychiatr Dis Treat 2014;10:499-506

10 Sharma A, Karande S, Sayal P, Ranadive N, Dwivedi N. Spinal intramedullary arachnoid cyst in a 4-year-old girl: a rare cause of treatable acute quadriparesis: case report. J Neurosurg 2005; 102(4, Suppl)403-406 